\title{
Derived Meanings of the Verbs "Нести-Носить" In Russian Proverbs
}

\author{
Emre Kirli \\ Ardahan University, Faculty of Humanities and Letters \\ Department of Russian Language and Literature \\ E-mail: emrekirli@ardahan.edu.tr
}

\begin{abstract}
Turkish and Russian languages, which belong to separate language families in terms of origin, differ structurally. For this reason, it is often difficult for Turkish learners of Russian to comprehend Russian grammar rules and find contexts to apply these rules. Moreover, semantic memorization of many concepts in the process of learning Russian poses a major challenge for Turkish students, who do not have an actual verb of motion category and prefixes in their native language. To this end, the present study will focus on the verbs of motion "нести-носить", derived thorugh the use of prefixes, and will intend to evaluate them from formal and semantic aspects in the light of examples selected from Russian idioms and from the Turkish point of view.
\end{abstract}

Key Words: Russian, Idioms, Hecmu-Hocumb, Verbs of Motion, Connotation

DOI: $10.7176 / J S T R / 6-07-12$

\section{Rusça Deyimlerde Ön Ekli “Нести - Носить” Hareket Fiillerinin Yan Anlamları}

Özet

Köken bakımından ayrı dil ailelerine mensup olan Türkçe ve Rusça, yapısal açıdan farklılıklar göstermektedir. Bu nedenle, Rusça öğrenen Türk öğrenciler için Rusça dilbilgisi kurallarını anlamak ve de söz konusu kurallara uygulama sahası bulabilmek çoğu zaman oldukça zordur. Ana dillerinde ayrılmış bir hareket fiili kategorisi ve ön ek unsuru bulunmayan Türk öğrenciler, Rusça öğrenme süreçlerinde kuşkusuz çoğu kavramı zihinlerinde anlamsal olarak bir yere oturtamazlar. Bu bağlamda; çalışmamızda ön ek ile türetilmiş “нести-носить” hareket fiilleri odağa alınacak, Rusça deyimler arasından seçilmiş örnekler ışığında ve Türk bakış açısıyla biçimsel ve anlamsal açılardan değerlendirilmeye çalışılacaktır.

Anahtar Kelimeler: Rusça, Deyim, Hecmu-Hocumb, Hareket Fiilleri, Yan Anlam.

\section{Giriş}

Türkçede fiil (eylem); Olumlu veya olumsuz olarak çekimli durumda zaman kavramı taşıyan veya zaman kavramı ile kişi kavramı veren kelime, eylemdir. [TDK] Türkçede fiiller; haber ve dilek kipi ekleriyle zaman kavramını ve nasıl yapıldığını, şahıs ekleri ile de eylemin kim tarafından gerçekleştiğini belirtirler ve iş, durum, oluş olmak üzere üç ana başlıkta incelenebilirler.

Rusçada fiil (eylem): konuşmanın bir parçası olarak bir eylemi ya da koşulu ifade eden; zaman, kişi, sayı (şimdiki/geniş zamanda tekillik-çoğulluk), cinsiyet (geçmiş zamanda), ortaç (sıfat fiil) ve transgresif (Baltık ve Slav dillerinde görülen özel bir fiil biçimidir. Tesadüfen ilerleyen veya takip eden bir eylemi ifade eder. Bir tür mastar veya ortaç olarak kabul edilir), eylemin bitmiş ve bitmemişliğine göre kümelere ayrilan bir cümle ögesidir. [OJEGOV]

Rusça fiil kategorilerinden biri hareket fiilleridir. Türkçede de buna karşıllk gelen fiiller bulunmaktadır; fakat hareket fiillerinin olarak ayrı bir kümeye tabi tutulmadıkları görülmektedir. Hareket fiilleri; özel bir sözcük-semantik fiil grubu oluşturan eylemsel fiillerin çeşitlerinden biridir ve tür çiftleri oluşturmayan on sekiz çift fiil (bitmişlik ve bitmemişlik açısından) ile temsil edilir: "бexamb (tek yönlü 
eylem)-беzamb (çok yönlü eylem)/koşmak; бpecmu (tek yönlü eylem)-бpodumb (çok yönlü eylem)/ dolaşmak, dolanmak; везти (tek yönlü eylem)-возить (çift yönlü eylem)/ herhangi bir taşıt ile (yük hayvanı da dâhil) taşımak, getirmek-götürmek; вести (tek yönlü eylem)-водumb (çok yönlü eylem)/ (taşıt kullanılmadan)götürmek, yönlendirmek; zнать (tek yönlü eylem) -гонять (çok yönlü eylem)/ kovmak, gütmek, гнаться (tek yönlü eylem)-гоняться (çok yönlü eylem)/ kovalamak, takip etmek; examb (tek yönlü eylem)-eздumb (çok yönlü eylem)/ (taşıt ile)gitmek-gelmek, uдmu (tek yönlü eylem)xодumb (çok yönlü eylem)/ (yaya olarak) gitmek-gelmek, кamumb (tek yönlü eylem)- кamamb (çok yönlü eylem)/ yuvarlamak, hizlıca hareket etmek; катиться (tek yönlü eylem)-катаmьcя (çok yönlü eylem)/ yuvarlanmak, hızlıca hareket etmek; лезть (tek yönlü eylem)- лазить (çok yönlü eylem)/ tırmanmak; лететь (tek yönlü eylem)- лemamb (çok yönlü eylem)/ uçmak (uçma yetisi olan taşıtlar da dâhil), нести (tek yönlü eylem)- носить (çok yönlü eylem)/ taşımak, getirmek-götürmek, неcmucb (tek yönlü eylem)- носиться (çok yönlü eylem)/ öne doğru hızla hareket etmek, hızlıca koşmak; nльть (tek yönlü eylem)- плавать (çok yönlü eylem)/ yüzmek (yüzme yetisi olan taşıtlar da dâhil), ползти (tek yönlü eylem)- ползать (çok yönlü eylem)/ sürünmek, maщฺить (tek yönlü eylem)- macкаmb (çok yönlü eylem)/ sürüklemek, taşımak; maщиться (tek yönlü eylem)- macкаться (çok yönlü eylem)/ ayağını sürüyerek yürümek, (taşıt ile ya da yaya) yavaş gitmek-gelmek.” Bu fiiller, ön ek almadan bitmemiş fiil durumundadırlar. Her bir hareket fiili çifti; yapılan hareketin yönünü (tek yönlü- çok yönlü), eylemin sürekliliğini ya da tek seferliğine yapıldığını belirtir. Ön ek alan hareket fiilleri; eylemin, anlamsal olarak, tamamlanıp-tamamlanmama durumunu ve eylemin sürekliliği hususunu değiştirebilir, hatta eylemi gerçek anlamından uzaklaştırarak, gerçek anlamını kaybetmesini sağlayabilirler.

Türkçe sondan eklemeli bir dil olduğu için fiil türetiminde ön ek ve son ek almamaktadır. Türkçede fiil türetiminde yapım eklerinden (isimden fiil yapma, fiilden fiil yapma ekleri vb.) faydalanılır. Fakat Rusçada, bunun tam tersine, fiil türetiminde ön ek, orta ek ve son ek kullanılmaktadır. Ön ek; bazı yabancı dillerde kökün önüne gelerek sözcüğe belirli bir anlam katan ektir. (TDK) Her bir ön ek, önüne geldiği her bir fiile farklı bir anlam katar. Hareket fiilleri ön ek aldıklarında, genellikle yapılan eylemin


içerisine girmek gibi. Burada “в/во-" ön eki; gitmek/gelmek eyleminin, bir yerin içerisine doğru yapıldığını belirtmektedir. Fakat hareket fiilleri, bazen aldıkları ön ekler ile asıl anlamlarını kaybederek yan anlam kazanabilirler, bu durum özellikle deyim ve atasözlerinde göze çarpmaktadır.

\section{"Hecmu-носиmb" Hareket Fiili İçeren Rusça Bazı Deyimlerin İ́celenmesi:}

1. Носить воду решетом: делать что-либо заведомо впустую, без результата.

a. Birebir Türkçe çevirisi "parmaklıkla su taşımak”tır. Sonuç elde edilemeyecek, boş işlerle uğraşmak, boşuna uğraşmak anlamında kullanılır.

b. Türkçe karşılığ "havanda su dövmek" olarak kabul edilebilir.

c. Bu deyimde носить fiili ön ek almamıştır.

Нести fiili burada ön ek almamış ve gerçek anlamında kullanılmaktadır, yani hareket fiili özelliğini kaybetmemiştir.

2. Какой ветер занес/каким ветром занесло:

a. Birebir Türkçe çevirisi "hangi rüzgâr getirdi? / hangi rüzgâr tarafindan getirildi"dir. Bir kişinin herhangi bir yerde, hangi şartlardan dolayı ortaya çıkması durumunu sorgularken kullanılır.

a. Türkçe karşıllı̆̆ “ "hangi rüzgâr attı?” olarak kabul edilebilir.

b. Носить fiili за- ön eki alarak заносить fiilini oluşturmuştur. Ön ek alan hareket fiillerinin çoğu; ön eki aldıktan sonra bitmiş fiil (совершенный вид) grubuna dâhil olmalarına rağmen, носить kök fiili sürekli ve çok yönlü eylem anlamı taşımasından dolayı заносить fiili de türemiş ve bitmemiş fiil (несовершенный вид) özelliğine sahiptir. 3aносить fiili aldığı зa- ön ekinden dolayı "birini ya da bir şeyi uzak bir yerden alıp getirmek/götürmek" anlamını kazanmıştır.

c. Нести fiili за- ön eki alarak занести fiilini oluşturmuştur. Занести fiili kurala uygun şekilde, ön ek almasından dolayı türemiş ve bitmiş fiiller (совершенный вид)


ekinden dolayı "birini ya da bir şeyi uzak bir yerden alıp getirmek/götürmek" anlamını kazanmıştır.

3a- ön ekinin нести-носить fiiline kattığı anlamdan dolayı biçimsel ve anlamsal olarak hareket fiili özelliğini korumaktadır.

3. В Возносить/вознести (превозносить) до небес: 
a. Birebir Türkçe çevirisi ve Türkçe karşılığı “göklere çıkarmak”tır. Birini ya bir şeyi aşırı derecede övmek anlamında kullanılır.

b. Носить fiili воз- ön eki alarak возносить fiilini oluşturmuştur. Ön ek alan hareket fiillerinin çoğu; ön eki aldıktan sonra bitmiş fiil (совершенный вид) grubuna dâhil olmalarına rağmen, носить kök fiili sürekli ve çok yönlü eylem anlamı taşımasından dolayı возносить fiili de türemiş ve bitmemiş fiil (несовершенный вид) özelliğine sahiptir. $\underline{\text { Boз }}$ носить fiili aldığı во3- ön ekinden dolayı "yukarıya doğru kaldırmak" anlamını kazanmıştır.

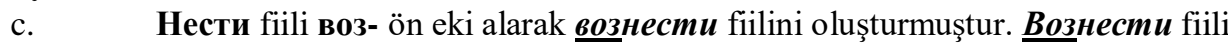
kurala uygun şekilde, ön ek almasından dolayı türemiş ve bitmiş fiiller (совершенный вид) grubunda olup eylemin sürekliliği ve çok yönlülüğü sona ermiştir. Возинести fiili aldığ1 возön ekinden dolayı "yukarıya doğru kaldırmak" anlamını kazanmıştır.

Bo3- ön eki genellikle edebi dilde ve şaka ya da ironi yaparken kullanılır. Bu nedenle нести-носить fiili, hareket fiili anlamını kaybetmiş ve yan anlam kazanmıştır.

\section{4. В Выносить/вынести (нести) на своих (собственных) плечах:}

a. Birebir Türkçe çevirisi “(kendi) omuzlarında taşımak”tır. Herhangi bir kimsenin yardımı olmadan, bağımsız olarak bütün zorlukların üstesinden gelmek anlamında kullanilır.

b. Türkçe karş1l.ğ kabul edilebilir.

c.

Носить fiili вы- ön eki alarak выносить fiilini oluşturmuştur. Ön ek alan hareket fiillerinin çoğu; ön eki aldıktan sonra bitmiş fiil (совершенный вид) grubuna dâhil olmalarına rağmen, носить kök fiili sürekli ve çok yönlü eylem anlamı taşımasından dolayı вblносить fiili de türemiş ve bitmemiş fiil (несовершенный вид) özelliğine sahiptir. $\underline{\boldsymbol{B b l}_{\mathbf{b}}}$ носить fiili aldığ1 вы- ön ekinden dolayı "bir şeye dayanmak, bir süre sabretmek" anlamını kazanmıştır.

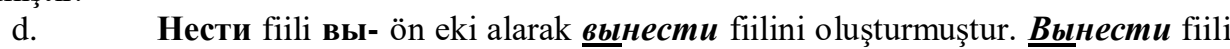
kurala uygun şekilde, ön ek almasından dolayı türemiş ve bitmiş fiiller (совершенный вид) grubunda olup eylemin sürekliliği ve çok yönlülüğü sona ermiştir. Вықнести fiili aldığ1 вы- ön ekinden dolayı "bir şeye dayanmak, bir süre sabretmek" anlamını kazanmıştır.

Вы- ön ekinin нести-носить fiiline kattığı anlamdan dolayı hareket fiili anlamını kaybetmiş ve yan anlam kazanmıştır.

\section{5. Выносить/官нести сор из избы:}

a. Birebir Türkçe karş1lı̆̆1 “kulübeden çöp çıkarmak"tır. Yakın insanların arasında yapılan kavgaları, tartışmaları ya da başkalarının bilmemesi gereken bir şeyi ifşa etmek anlamında kullanılır.

b. Türkçe karşılığı "reklam etmek, ilan etmek, açı̆̆a vurmak, afişe etmek" olarak kabul edilebilir.

c. Носить fiili вы- ön eki alarak выносить fiilini oluşturmuştur. Ön ek alan hareket fiillerinin çoğu; ön eki aldıktan sonra bitmiş fiil (совершенный вид) grubuna dâhil olmalarına rağmen, носить kök fiili sürekli ve çok yönlü eylem anlamı taşımasından dolayı

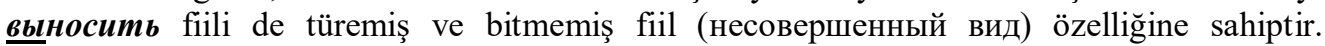

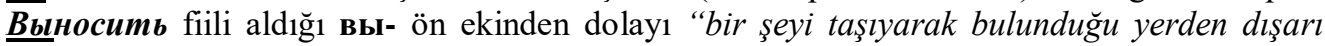
taşımak" anlamını kazanmıştır.

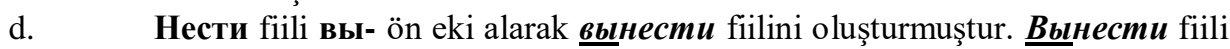
kurala uygun şekilde, ön ek almasından dolayı türemiş ve bitmiş fiiller (совершенный вид)

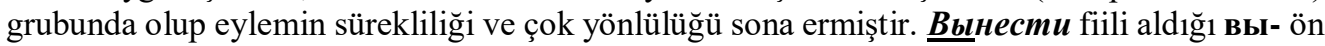
ekinden dolayı "bir şeyi taşıyarak bulunduğu yerden dışarı taşımak, çıkarmak" anlamını kazanmıştır.

Вы- ön ekinin нести-носить fiiline kattığı anlamdan dolayı biçimsel olarak hareket fiili olmasına rağmen, deyimde anlamsal olarak hareket fiili özelliğini yitirmiştir.

\section{Sonuc}

Çalışma içerisinde birincil olarak fiil kavramının tanımı yapılmış, daha sonra genel hatlarıyla hareket fiilleri ile ilgili bilgi verilmiştir. On yedi adet hareket fiili çifti Türkçe karşılıkları ve anlamsal farklılıklarıyla tanıtılmaya çalışılmıştır. Konunun özünü oluşturan Rusça deyimlerde ön ekli “несmи 
nocumb" hareket fiilleri tarafımızca Türkçeye çevrilmiş, biçimsel ve anlamsal açıdan değerlendirilmelerinin yanı sıra söz konusu deyimler içerisinde edindikleri yan anlamlar açıklanmıştır. Çalışmaya konu edinilen, “нести-носить” " hareket fiili içeren Rusça deyimler üzerinde yapılan bu çok yönlü analiz ile Türk öğrencilerin Rus dilini öğrenme süreçlerinin kolaylaştırılması hedeflenmiştir. Bu sayede Rusça öğrenmek isteyen Türk öğrencilerin, farklı bir dil ailesine mensup olan Rusça dilbilgisini daha kolay edinebilmeleri sağlanmış ve deyimler üzerinden, öğrencilere hedef dilin somut olmayan kültürel mirası tanıtılmıştır.

\section{Kaynakça}

Akademiya nauk SSSR İnstitut russkogo yazıka, Russkaya grammatika, Cilt I, Nauka Moskova, 1980.

Aksoy Ömer Asım, Atasözleri ve Deyimler Sözlüğ̈̈, Cilt 2 Deyimler Sözlüğü, İnkilap Kitabevi, 2008.

Dal Vladimir İ., Poslovitsı russkogo naroda: Sbornik, Cilt I, II. Baskı, Moskova, 1984.

Ojegov S. İ., Tolkovly slovar Ojegova, https://dic.academic.ru/dic.nsf/ogegova/39074. Erişim Tarihi: 11.02.2020.

TDK, Güncel Türkçe Sözlük, https://sozluk.gov.tr. Erişim Tarihi: 13.02.2020.

Tikhonov Aleksandr N., Slovoobrazovatelnıy slovar russkogo yazıka, ACT, Moskova, 2014.

Vinogradov V. V., Russkiy yazık (Grammatiçeskoye uçeniye o slove), pod red. G. A. Zolotovoy, 4. baskı, Moskova, Russkiy Yazık, 2001. 